\title{
THE DETECTION OF ENCAPSULATED AND NON-ENCAPSULATED SPECIES OF TRICHINELLA SUGGESTS THE EXISTENCE OF TWO EVOLUTIVE LINES IN THE GENUS
}

\author{
POZIO E.*, ZARLENGA D.S.** \& LA ROSA G.*
}

\section{Summary :}

In recent years, the discovery of many non-encapsulated isolates of Trichinella, designated Trichinella pseudospiralis and the identification of a new non-encapsulated species, Trichinella papuae, has revealed that the biomass of the genus Trichinella does not only include the well known encapsulated species (T. spiralis, T. nativa, $T$. britovi, $T$. murrelli, and $T$. nelsonil but also includes geographically disseminated, non-encapsulated species that represent important biological entities in the genus. Larvae of the first stage $\left(L_{1}\right)$ of both non-encapsulated and encapsulated species are able to penetrate the muscle cell and induce a dedifferentiation of this cell. But following this point in the parenteral cycle, non-encapsulated and encapsulated species diverge with respect to their developmental strategies where $L_{1}$ of encapsulated species are able to induce the nurse cell to synthesize collagen, unlike non-encapsulated larvae which do not induce collagen production. The presence or absence of a collagen capsule is of great importance in the natural cycle of these parasites in that it allows the encapsulated larva to survive to substantially longer periods of time and therefore remain infective even within putrefied muscle tissue.

KEY WORDS : Trichinella, encapsulated larvae, non-encapsulated larvae, evolution.

\section{NATURAL INFECTIONS OF ANIMALS AND HUMANS WITH NON-ENCAPSULATED LARVAE OF TRICHINELLA}

$\mathrm{N}$ on-encapsulated Trichinella larvae were first discovered in a raccoon dog (Nyctereutes procyonoides) of Caucasus (Russia) and subsequently described as a new species named Trichinella pseudospiralis Garkavi, 1972. Since 1956, Trichinella infections suspected to be non-encapsulated larvae were documented in birds of Alaska, Iowa, Spain and California (Pozio et al., 1992). Furthermore, Trichinella pseudospiralis was identified in two rooks and a corsac

\footnotetext{
* Laboratory of Parasitology, Istituto Superiore di Sanità, viale Regina Elena 299, 00161 Rome, Italy.

** USDA, ARS, LPSI, Immunology and Disease Resistance Laboratory, Beltsville, MA 20705, USA.

Correspondence: Istituto Superiore di Sanità, viale Regina Elena 299, 00161 Rome, Italy.

Tel.+390649902304 - Fax+390649387065 - e-mail: pozio@iss.it
}

fox from Kazakhstan, and in a mole rat from India as confirmed by cross-breeding experiments (Shaikenov \& Boev, 1983). Between 1990 and 1992, a focus of T. pseudospiralis was identified in marsupials and birds of Tasmania (Obendorf et al., 1990; Obendorf \& Clarke, 1992). Most recently, T. pseudospiralis was documented in birds from Alabama, Kazakhstan and Italy, and in domestic pigs from Kamchatka. In addition, non-encapsulated larvae were found in Tula region and Krasnodar territory of Russia, in a brown rat from Kamchatka, a wild boar from France, and in raccoon dogs, brown rat and wild boar from Finland (Pozio, 2000). The first human infection with T. pseudospiralis was described as occurring in a woman, who acquired the infection in Tasmania (Andrews et al., 1995). Three additional trichinellosis outbreaks caused by $T$. pseudospiralis occurred in Thailand, Kamchatka and France (Jangwutiwes et al., 1998; Britov, 1997; Ranque et al., 2000).

Between 1988 and 1998, non-encapsulated larvae of Trichinella were detected in domestic and wild pigs from a remote area of Papua New Guinea and were originally classified as T. pseudospiralis; however, upon further examination and additional biological and molecular studies, this parasite was classified as a new species, designated Trichinella papuae (Pozio et al., 1999).

\section{MARKERS BETWEEN ENCAPSULATED AND NON-ENCAPSULATED SPECIES}

1 The most important morphological marker between encapsulated and non-encapsulated species of Trichinella is the presence of a collagen capsule surrounding the nurse cell-larva complex of encapsulated species. The presence of this collagen capsule imparts essential differences in the host-parasite relationship with respect to: 1) the physiology (acquisition of nutrients, expulsion of catabolites, etc.); 2) the immunology, i.e., the antigenic stimulus of the immune response of the host; and 3) the transcription of regulatory genes activating type 4 and 6 collagen production in encapsulated species (Despommier, 
1998). The presence of the capsule is of great importance also in the biology of these parasites where nonencapsulated larvae are capable of easily moving among muscle cells, whereas encapsulated larvae do not.

Other deficiencies include the host range of nonencapsulated larvae which includes mammals and birds, whereas encapsulated larvae appear not to develop in avian species. Also, the survival of larvae in decaying muscles is high for encapsulated larvae which demonstrate resistance to freezing and less sensitivity to high temperatures; characteristics not observed in non-encapsulated larvae. In this regard, geographical distribution of encapsulated species can be correlated with the climate (with the exception of $T$. spiralis, which was introduced everywhere by humans), whereas $T$. pseudospiralis is more cosmopolitan in nature with few differences among populations from different continents (Zarlenga et al., 1996). Furthermore, both non-encapsulated species of Trichinella are present in the Australian region, whereas encapsulated species of Trichinella have yet to be identified in a naturally infected animal from this zoogeographical region.

With respect to biochemical differences, we found that of 27 examined allozymes, encapsulated species showed one-six unique allozymes (4-22\%), whereas T. pseudospiralis showed 12 unique allozymes (45\%) (La Rosa et al., 1992). A plethora of molecular markers is useful to separate encapsulated from nonencapsulated species as well. Differences in sequence length within expansion segment $\mathrm{V}$ can be observed by multiplex-PCR (Zarlenga et al., 1999) and by PCRSSCP (Gasser et al., 1998). Variation within the cytochrome c-oxidase gene (Nagano et al., 1999) as well as the 43 and $53 \mathrm{kDa}$ ES protein genes (Wu et al., 1999) can be detected by PCR-RFLP.

\section{DISCUSSION}

The existence of morphological, biological, zoogeographical, biochemical and molecular markers that differentiate encapsulated and nonencapsulated species of Trichinella, strongly suggest the presence of two evolutive lines in this genus. Encapsulated larvae in the decomposing carcass may be analogous to the species-dispersion via eggs or larvae of other nematodes where both are protected from their local environment until host-derived queues initiate further development of the parasite. The disparate abilities of encapsulated and non-encapsulated species-types to induce collagen synthesis in the nurse cell could have been the key factor which split these nematodes into two distinct phyletic lines.
We propose that these nematodes be more clearly delineated than their present species level classifications, and suggest that the genus Trichinella be split in two genera, the first encompassing encapsulated species (T. spiralis, T. nativa, T. britovi, T. murrelli, and T. nelsoni) and genotypes (Trichinella T6, T8 and T9) and the second encompassing non-encapsulated species T. pseudospiralis and T. papuae.

\section{CONCLUSIONS}

$\mathrm{F}$ uture research should focus on: 1) identifying genomic-based genetic markers for encapsulated and non-encapsulated species; 2) identifying differences between encapsulated and non-encapsulated larvae in escaping the host immunity; 3 ) understanding the purpose for the capsule formation and how-nonencapsulated species survive in nature; and 4) evaluating the biomass of encapsulated and non-encapsulated worms in nature and their relative association with domestic animals and humans.

\section{REFERENCES}

Andrews J.R.H., Bandi C., Pozio E., Gomez Morales M.G., AINSWORTH R. \& ABERNETHY D. Identification of Trichinella pseudospiralis from a human case using random amplified polymorphic DNA. American Journal of Tropical Medicine and Hygiene, 1995, 53, 185-188.

Britov V.A. Trichinellosis in Kamchatka. Wiadomosci Parazytologiczne, 1997, 43, 287-288

Despommier D.D. How does Trichinella spiralis make itself at home? Parasitology Today, 1998, 14, 318-323.

Gasser R.B., Zhu X., Monti J.R., Dou L., Cai X. \& Pozio E. PCR-SSCP of rDNA for the identification of Trichinella isolates from mainland China. Molecular and Cellular Probes, $1998,12,27-34$.

Jongwutiwes S., Chantachum N., Kraivichian P., Siriyasatien P., Putaporntip C., Tamburrini A., La Rosa G., SreesunpasiriKul C., Yingyourd P. \& Pozio E. First outbreak of human trichinellosis caused by Trichinella pseudospiralis. Clinical Infectious Diseases, 1998, 26, 111-115.

La Rosa G., Pozio E., Rossi P. \& Murrell K.D. Allozyme analysis of Trichinella isolates from various host species and geographic regions. Journal of Parasitology, 1992, 78, 641-646.

Nagano I., Wu Z., Matsuo A., Pozio E. \& Takahashi Y. Identification of Trichinella genotypes by polymerase chain reaction-restriction fragment length polymorphism of mitochondrial cytochrome c oxidase subunit I gene. International Journal for Parasitology, 1999, 29, 1113-1120.

OBENDORF D.L. \& ClaRKE K.P. Trichinella pseudospiralis infections in free-living Tasmanian birds. Journal of the Helminthological Society of Washington, 1992, 59, 144-147. 
Obendorf D.L., Handlinger J.H., Mason R.W., Clarke K.P., Forman A.J., HoOper P.T., Smith S.J. \& HoldsworTh M. Trichinella pseudospiralis infection in Tasmanian wildlife. Australian Veterinary Journal, 1990, 67, 108-110.

Pozio E. The domestic, synanthropic and sylvatic cycles of Trichinella and the flow among them. Veterinary Parasitology, 2000, (in press).

Pozio E., Owen I.L., La Rosa G., Sacchi L., Rossi P. \& Corona S. Trichinella papuae n. sp. (Nematoda), a new non-encapsulated species from domestic and sylvatic swine of Papua New Guinea. International Journal for Parasitology, 1999, 29, 1825-1839.

Pozio E., Shaikenov B., La Rosa G. \& Obendorf D.L. Allozymic and biological characters of Trichinella pseudospiralis isolates from free-ranging animals. Journal of Parasitology, 1992, 78, 1087-1090.

Ranque S., Faugere B., Pozio E., la Rosa G., Tamburrini A., Pellissier J.F. \& Brougui P. Trichinella pseudospiralis human outbreak in Europe. Emerging Infectious Diseases, 2000, 6, 543-547.

Shaikenov B. \& Boev S.N. Distribution of Trichinella species in the Old World. Wiadomosci Parazytologiczne, 1983, 29, 595-608.

Wu Z., Nagano I., Pozio E. \& Takahashi Y. Polymerase chain reaction-restriction fragment length polymorphism (PCR-RFLP) for the identification of Trichinella isolates. Parasitology, 1999, 118, 211-218.

ZARLenga D.S., AsChenBRenNer R.A. \& Lichtenfels J.R. Variations in microsatellite sequences provide evidence for population differences and multiple ribosomal gene repeats within Trichinella pseudospiralis. Journal of Parasitology, 1996, 82, 534-538.

Zarlenga D.S., Chute M.B., Martin A. \& Kapel C.M.O. A multiplex PCR for unequivocal differentiation of six encapsulated and three non-encapsulated genotypes of Trichinella. International Journal for Parasitolology, 1999, 29, 41-49. 